\title{
Photo Acoustic Thermal for Human Bone Characterization: A Feasibility Study
}

\author{
James Rizkalla1, Vinay Kumar Suryadevara ${ }^{2}$, Ashok Kumar Thella², Ahdy Helmy¹, \\ Paul Salama², Maher E. Rizkalla2,3 \\ ${ }^{1}$ Indiana University School of Medicine, Indianapolis, IN, USA \\ ${ }^{2}$ Electrical and Computer Engineering, Indiana University Purdue University Indianapolis (IUPUI), Indianapolis, \\ IN, USA \\ ${ }^{3}$ Integrated Nanosystems Development Institute (INDI), Indiana University Purdue University Indianapolis \\ (IUPUI), Indianapolis, IN, USA \\ Email: mrizkall@iupui.edu
}

Received 8 July 2016; accepted 9 August 2016; published 12 August 2016

Copyright (C) 2016 by authors and Scientific Research Publishing Inc.

This work is licensed under the Creative Commons Attribution International License (CC BY). http://creativecommons.org/licenses/by/4.0/

(c) (i) Open Access

\begin{abstract}
The possible features of photo acoustic tomography (PAT) in medical research and practice, including applications in orthopedics and cardiovascular areas, among others, have motivated the emphasis of this study towards human bone applications. PAT modality is an emerging approach that features safety and greater penetration depth compared to other modalities such as X-ray and microwave. The high-resolution images and safety related to PAT modality are attributed to the scattering properties of ultrasound as compared to light within a human tissue. PAT brought considerable attention from the medical research community to target optimum parameters for practical models. It includes source frequency penetration depth, dynamic temperature responses, and acoustic pressure throughout the multilayer structure of the human tissues. In this work, the acoustic pressure and the bio-heat equations were analyzed for power distribution and penetration depth, covering the basic principles of PAT within the human body. Three sources with three different heat energy pulses; $1 \mathrm{~s}, 3 \mathrm{~s}$, and 5 s, were considered in order to study the rise time and fall time dynamic responses inside the bone material. The computer simulation was designed to simulate the human tissue at $1 \mathrm{MHz}$ with an acoustic pressure of $1 \mathrm{MPa}$. A penetration depth for all sources was estimated to be near $4 \mathrm{~cm}$ with a temperature change from $0.5 \mathrm{~K}$ to near $1 \mathrm{~K}$ over a period of $10 \mathrm{~s}$. The simulation data provide promising results when taken to the next level of practical implementation. The $4 \mathrm{~cm}$ penetration depth range may enable the researchers to investigate multiple layers within the human body, leading to non-invasive deterministic approach. The simulation presented here will serve as a pilot study towards photoacoustic applications in orthopedic applications.
\end{abstract}

\section{Keywords}

Photoacoustic Tomography, PAT, PA, Ortho, COMSOL

How to cite this paper: Rizkalla, J., Suryadevara, V.K., Thella, A.K., Helmy, A., Salama, P. and Rizkalla, M.E. (2016) Photo Acoustic Thermal for Human Bone Characterization: A Feasibility Study. J. Biomedical Science and Engineering, 9, $445-449$. http://dx.doi.org/10.4236/jbise.2016.99040 


\section{Introduction}

The constraints associated with the safety in microwave and X-ray imaging, the high resolution inquired in medical imaging and limitation of the penetration depth for the energy inside human body, have raised concerns by medical researchers in achieving and accommodating high performance modality that provides the patient with safety and accepted resolution. The reliability of the modality is quite important in the diagnostic process; therefore, the image quality is of high demand in the practical model of the diagnostic system. In the past decade, the PA tomography has offered acceptable modality that overcomes such challenges [1] [2]. The concept of this modality is based on the absorption of the optical energy into acoustic energy. Since the wavelength of the acoustic wave is much higher than that of the optical waves, the PA based modalities are advantageous when dealing with the speed of blood flow [3], and the metabolic rate of oxygen [4]. Since the PA imaging provides higher penetration depth, its applications in vascular imaging is unique. In a comparative study between this modality and others, the PA can support higher resolution at a greater depth within the human tissue or bone layer. The contrast level is a big feature in this case with minimum artifacts. In comparison with the X-ray, the PA will not result in blood ionizing case, and rather, the application of the laser illumination beam in the PA modality is non-ionizing process. In terms of the high-speed process modality, this one features a better speed as compared to the MRI imaging. Furthermore, this approach may feature applications to patients who may not be eligible to use MRI for limitation to pace makers or others. The broader impact and uniqueness of the use of this modality have attracted research interests in vascular surgery, neurology, cardiology, orthopedics, etc. [5]-[11]. The input source in this case is thermal, while the output is both thermal and acoustic.

\section{Mathematical Model}

The acoustic wave equation used by COMSOL is given by:

$$
\nabla \cdot\left(-\frac{1}{\rho c}\left(\nabla P_{t}-q_{d}\right)\right)-\frac{k_{e q}^{2} P_{t}}{\rho c}=Q_{m}
$$

where $P_{t}=P+P_{b}$, and $P_{b}$ is bio thermal pressure, $P$ is the acoustic pressure, and $k_{e q}^{2}=\left(\frac{\omega}{C c}\right)^{2}-\left(\frac{m}{r}\right)^{2}$,

$$
C_{c}=\frac{\omega}{k}
$$

Boundary conditions

$$
-n \cdot\left(-\frac{1}{\rho c}\left(\nabla P_{t}-q_{d}\right)\right)=0,
$$

where $m$ is the mass density, $r$ is the location in space, and $\omega$ is the radian frequency. The sound hard boundary equation, matching normal where $n$ is the unit vector normal to the surface. $P$ is the acoustic pressure, $c$ is the speed of sound, $\rho$ is the material density, and $k$ is the wave number.

The Bioheat equations are given as:

$$
\begin{gathered}
\rho C u . \nabla T+\nabla \cdot q=Q+Q_{b i o} \\
q=-k \nabla T . \\
Q_{b i o} \rho_{\rho b} \omega_{b}\left(T_{b}-T\right)+Q_{\text {met }}+\nabla \cdot q=Q+Q_{b i o}
\end{gathered}
$$

where $q$ is the progressing source via the various layers of the materials, $Q_{b i o}$ is the bio heat source, $T_{b}$ is the bio thermal temperature, and $\rho_{\rho b}$ is the mass density of the material under bio thermal effect.

The effect of the thermo acoustic takes place at the interface between the catheter and the bone material. Therefore, it is important to consider the penetration depth throughout the materials. The drop over the interface is related to the mismatch of the acoustic impedance. The thermal penetration depth is the distance that the heat may travel through. The phonons in the sound possess same characteristics as in heat, therefore, the characteristic length for the thermal interaction between two media may be characterized by $\delta$ given as:

$$
\delta^{2}=2 \kappa V_{m} / \omega C
$$


where $\kappa$ is the thermal conductivity, $V_{m}$ the molar volume, and $C$ is the molar heat capacity, given at constant pressure. In the simulation, the heat source 1 is given a constant number of $Q_{0}$ centered at $2.46 \mathrm{~cm}$, at a starting temperature $T_{0}$ (was given $293.6 \mathrm{~K}$ ) with a tissue of $2.46 \mathrm{~cm}$.

\section{Simulation Results}

The mathematical models presented in Section 2 above were combined by COMSOL software to present the thermal distribution and the acoustic wave spread out within the bone layer. The parameters of the human bones used in the simulation are presented in Table 1.

The data presented here was based on comparative study for three different sources providing energy providing energy for $1 \mathrm{~s}, 3 \mathrm{~s}$, and $5 \mathrm{~s}$. The amount of energy is then released into the bone material, providing the dynamic fall time response for different energies. The sound pressure level is presented in Figure 1. This was based on $1 \mathrm{MPa}$, and was allowed for near $4.6 \mathrm{~cm}$ distance. It is noticeable that the higher pressure occurs at a level of higher thermal energy. The change in pressure from $1 \mathrm{~s}$ energy to $3 \mathrm{~s}$ energy sources was not quite the same as the change from $3 \mathrm{~s}$ energy to $5 \mathrm{~s}$ energy, citing a non-linearity in the pressure distribution with the magnitude of the source energy. The thermal temperature contours for the three types of sources were given in Figure 2. It is clear that the contour profile as well as the temperature distribution between the three energy sources were different. The hot spot at the focus point differ from $0.44 \mathrm{~K}$ at $1 \mathrm{~s}$ to $2.9 \mathrm{~K}$ for $3 \mathrm{~s}$, and near $3.3 \mathrm{~K}$ at $5 \mathrm{~s}$. Figure 3 gives the dynamic temperature response; rise time and fall time, for the three sources of energy. The temperature difference between the focus and $0.5 \mathrm{~m}$ far from focus was reported to be near $0.5 \mathrm{~K}$, while for the $3 \mathrm{~s}$ source was found to be $0.7 \mathrm{~K}$, and for the $5 \mathrm{~s}$ source was found near $1 \mathrm{~K}$. Figure 4 presents the temperature distribution at the source site for $1 \mathrm{~s}$ and $2 \mathrm{~s}$ periods taken for the $1 \mathrm{~s}$ source. The intensity profile has been

Table 1. Properties for human bone (cancellous) at $1 \mathrm{MHZ}$.

\begin{tabular}{cccccc}
\hline Permittivity & $\begin{array}{c}\text { Elec. Cond. } \\
(\mathrm{S} / \mathrm{m})\end{array}$ & $\begin{array}{c}\text { Density } \\
\left(\mathrm{kg} / \mathrm{m}^{3}\right)\end{array}$ & $\begin{array}{c}\text { Heat Capacity } \\
\left(\mathrm{J} / \mathrm{kg} /{ }^{\circ} \mathrm{C}\right)\end{array}$ & $\begin{array}{c}\text { Therm. Cond. } \\
\mathrm{W} / \mathrm{m} /{ }^{\circ} \mathrm{C}\end{array}$ & $\begin{array}{c}\text { Heat Transfer Rate } \\
(\mathrm{ml} / \mathrm{min} / \mathrm{kg})\end{array}$ \\
\hline $2.49 \mathrm{E}+2$ & $9.04 \mathrm{E}-2$ & 1178 & 2274 & 0.31 & $\begin{array}{c}\text { Heat Generation } \\
\mathrm{Rate}(\mathrm{W} / \mathrm{kg})\end{array}$ \\
\hline
\end{tabular}
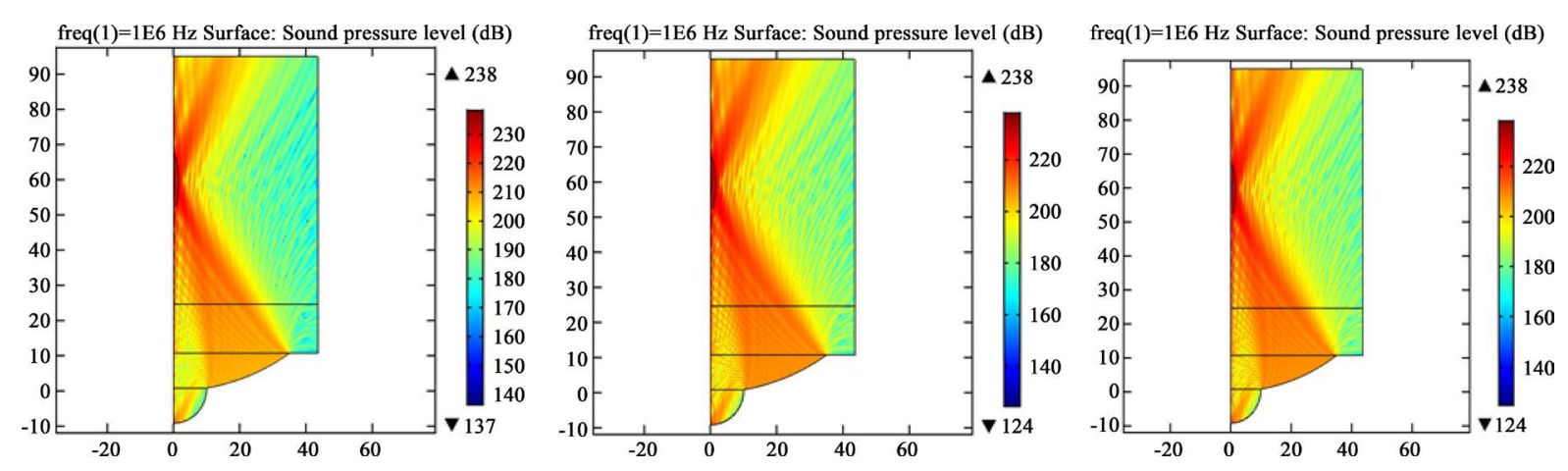

Figure 1. 2-D sound pressure for 1, 3 , and 5 second sources (given from left to right).
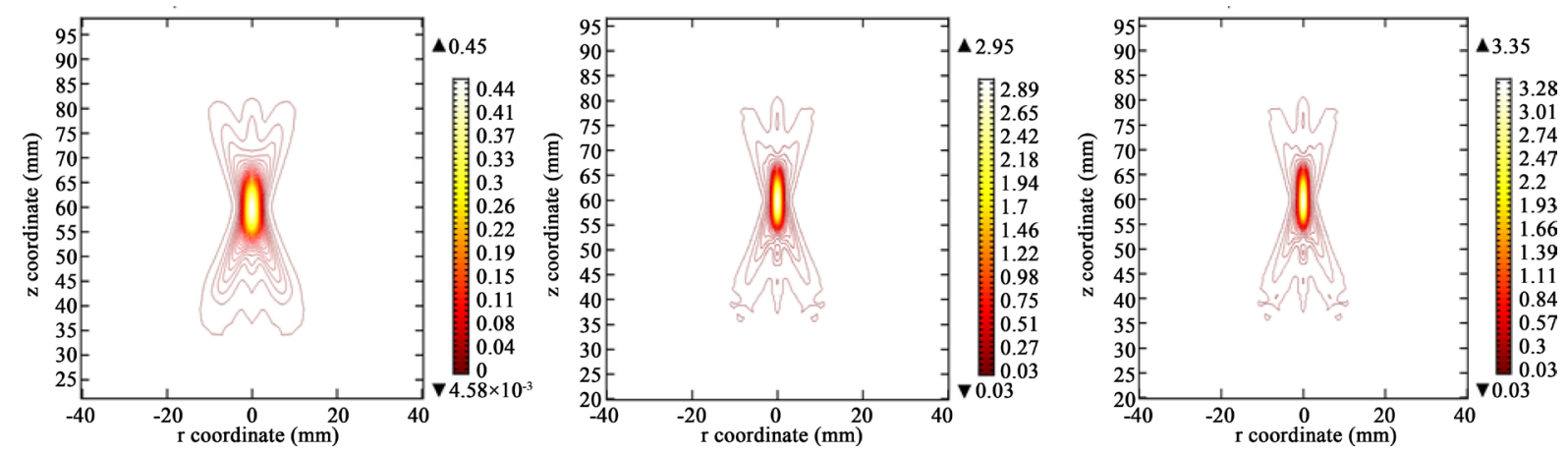

Figure 2. Temperature contours for 1, 3, and 5 second sources (given from left to right). 

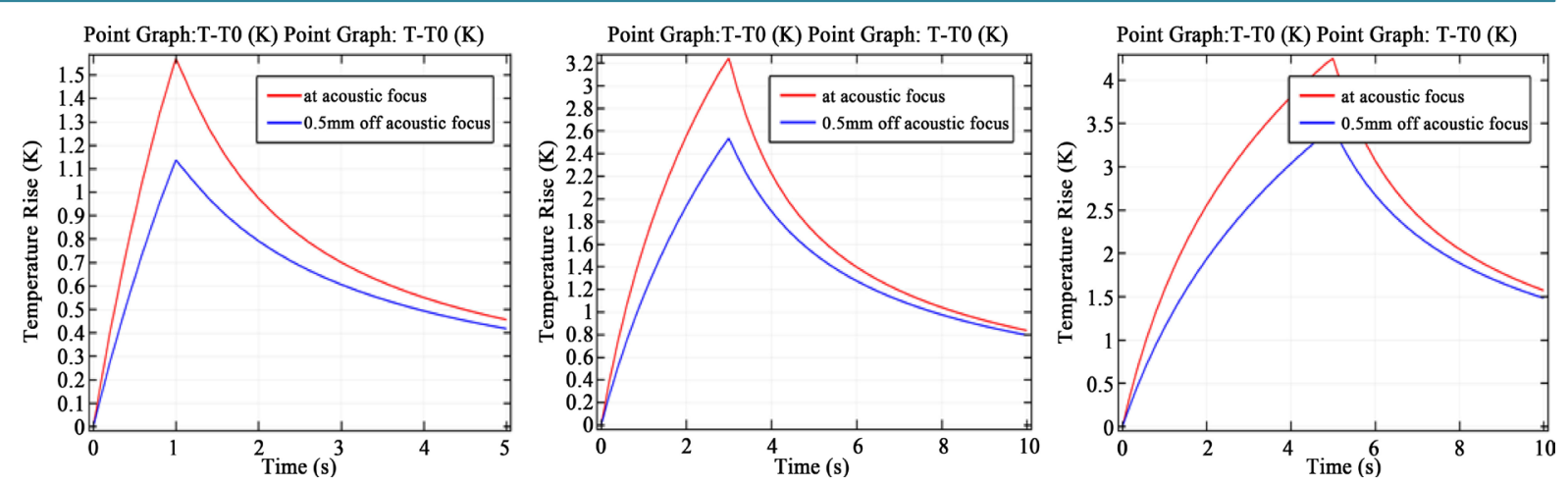

Figure 3. Temperature rise vs. time at focus and $0.5 \mathrm{~mm}$ off focus for 1,3 , and 5 second sources (given from left to right).

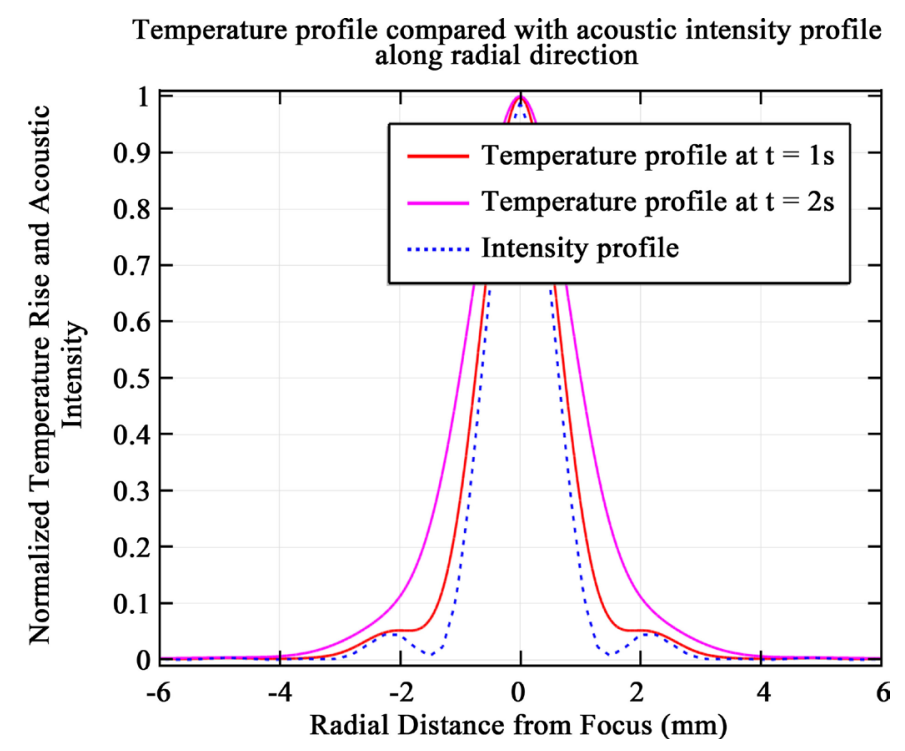

Figure 4. The temperature and acoustic dynamic profiles for $1 \mathrm{~s}$ and $2 \mathrm{~s}$.

found well proportional with the acoustic pressure. The theory supports power transmission for temperature and acoustic energy near $2.5 \mathrm{~cm}$ from both sides.

\section{Conclusion and Future Work}

The data presented here indicates the feasibility to have photo acoustic imaging that may penetrate to the $\mathrm{cm}$ range and diagnose multiple layers within the human body. The safety factor of this novel modality will bring research attention to future practical models. The work presented here serves as a first phase of a project that simulates multiple layers from the body skin, bone, and human arteries where fat cholesterol can be diagnosed. The properties of the acoustic reflected and transmitted powers in addition to the thermal expansion of the layers may be detected for the practical model, and this is reserved for future considerations. The various sources of energy emphasized the thermal response with a wide range of temperature difference from $0.5 \mathrm{~K}$ to $1 \mathrm{~K}$. This data give promising approach to detect the temperature distribution across the bone materials. A typical practical model then can be followed using infrared scanner to detect the temperature distribution within the materials and their boundaries. In the future, this approach may be expanded to cover multiple layers including fat material inside the human arteries. The application towards cardiovascular is reserved for future consideration.

\section{Acknowledgements}

The authors and co-authors offer their great appreciation for the INDI Center at IUPUI for their support during the work of this study. 


\section{References}

[1] Ke, H., Tai, S. and Wang, L.V. (2014) Photoacoustic Thermography of Tissue. Journal of Biomedical Optics, 19, 026003-026003. http://dx.doi.org/10.1117/1.JBO.19.2.026003

[2] http://www.pdfdrive.net/current-technology-and-challenges-for-medical-imaging-modalities-e3725189.html

[3] Capmany, J., Li, G., Lim, C. and Yao, J. (2013) Microwave Photonics: Current Challenges towards Widespread Application. Optics Express, 21, 22862-22867. http://dx.doi.org/10.1364/OE.21.022862

[4] El Sayed, M.J. and Zaghrini, E. (2013) Prehospital Emergency Ultrasound: A Review of Current Clinical Applications, Challenges, and Future Implications. Emergency Medicine International, 2013, Article ID: 531674. http://dx.doi.org/10.1155/2013/531674

[5] Xia, J., Yao, J. and Wang. L.V. (2014) Photoacoustic Tomography: Principles and Advances. Electromagnetic Waves (Cambridge), 147, 1-22. http://dx.doi.org/10.2528/PIER14032303

[6] Wan, Y., Liu, D. and Ebbini, E.S. (2010) Imaging Vascular Mechanics Using Ultrasound: Phantom and in Vivo Results. 2010 IEEE International Symposium on Biomedical Imaging: From Nano to Macro, 14-17 April 2010, 980-983. http://dx.doi.org/10.1109/ISBI.2010.5490152

[7] Suryadevara, V.K., Patil, S., Rizkalla, J., Helmy, A., Salama, P. and Rizkalla, M. (2016) Microwave/Thermal Analyses for Human Bone Characterization. Journal of Biomedical Science and Engineering, 9, 101-111. http://dx.doi.org/10.4236/jbise.2016.92006

[8] Chen, Z., Basarab, A. and Kouamé, D. (2016) Compressive Deconvolution in Medical Ultrasound Imaging. IEEE Transactions on Medical Imaging, 35, 728-737. http://dx.doi.org/10.1109/TMI.2015.2493241

[9] Tajbakhsh, N., Shin, J.Y., Gurudu, S.R. and Hurst, R.T. (2016) Convolutional Neural Networks for Medical Image Analysis: Fine Tuning or Full Training? IEEE Transactions on Medical Imaging, 35, 1299-1312. http://dx.doi.org/10.1109/TMI.2016.2535302

[10] http://www.itis.ethz.ch/virtual-population/tissue-properties/database/database-summary/

[11] Jaspard, F., Nadi, M. and Rouane, A. (2003) Dielectric Properties of Blood: An Investigation of Haematocrit Dependence. Physiological Measurement, 24, 137. http://dx.doi.org/10.1088/0967-3334/24/1/310

\section{Submit or recommend next manuscript to SCIRP and we will provide best service for you:}

Accepting pre-submission inquiries through Email, Facebook, LinkedIn, Twitter, etc.

A wide selection of journals (inclusive of 9 subjects, more than 200 journals)

Providing 24-hour high-quality service

User-friendly online submission system

Fair and swift peer-review system

Efficient typesetting and proofreading procedure

Display of the result of downloads and visits, as well as the number of cited articles

Maximum dissemination of your research work

Submit your manuscript at: http://papersubmission.scirp.org/ 